\title{
Event-related Potentials Associated with Masked Priming of Test Cues Reveal Multiple Potential Contributions to Recognition Memory
}

\author{
Anna M. Woollams ${ }^{1}$, Jason R. Taylor ${ }^{1}$, Frini Karayanidis ${ }^{2}$, \\ and Richard N. Henson ${ }^{1}$
}

\begin{abstract}
The relationship between recognition memory and repetition priming remains unclear. Priming is believed to reflect increased processing fluency for previously studied items relative to new items. Manipulations that affect fluency can also affect the likelihood that participants will judge items as studied in recognition tasks. This attribution of fluency to memory has been related to the familiarity process, as distinct from the recollection process, that is assumed by dual-process models of recognition memory. To investigate the time courses and neural sources of fluency, familiarity, and recollection, we conducted an event-related potential (ERP) study of recognition memory using masked priming of test cues and a remember $/$ know paradigm. During the recognition test, studied and unstudied words were preceded by a brief, masked word that was either the same or different. Participants decided quickly whether each item had been studied ("old" or "new"), and for items called
\end{abstract}

old, indicated whether they "remembered" (R) the encoding event, or simply "knew" (K) the item had been studied. Masked priming increased the proportion of $\mathrm{K}$, but not $\mathrm{R}$, judgments. Priming also decreased response times for hits but not correct rejections (CRs). Four distinct ERP effects were found. A medialfrontal FN400 (300-500 msec) was associated with familiarity (R, $\mathrm{K}$ Hits $>$ CRs) and a centro-parietal late positivity (500-800 msec) with recollection (R Hits $>$ K Hits, CRs). A long-term repetition effect was found for studied items judged "new" (Misses $>$ CRs) in the same time window as the FN400, but with a posterior distribution. Finally, a centrally distributed masked priming effect was visible between 150 and $250 \mathrm{msec}$ and continued into the 300-500 msec time window, where it was topographically dissociable from the FN400. These results suggest that multiple neural signals are associated with repetition and potentially contribute to recognition memory.

\section{INTRODUCTION}

The relationship between recognition memory and repetition priming is of long-standing interest. Recognition memory is measured by direct memory tests in which participants attempt to discriminate between items that are repeated from a previous study session ("old" items) and items that are not ("new" items). Repetition priming is normally measured in indirect memory tests, which make no reference to prior exposures to an item, but infer some form of memory by changes in accuracy or response time for old relative to new items (RichardsonKlavehn \& Bjork, 1988). Indeed, such changes can often occur in the absence of conscious memory for the prior exposure, an example of "implicit" memory (Schacter, 1987).

Many contemporary theories of memory assume that recognition memory and repetition priming reflect the operation of different memory systems in the brain (e.g., Gabrieli, 1998; Tulving \& Schacter, 1990). For example,

\footnotetext{
${ }^{1} \mathrm{MRC}$ Cognition \& Brain Sciences Unit, Cambridge, England, ${ }^{2}$ University of Newcastle, Australia
}

recognition has been claimed to depend on a declarative system within the medial-temporal lobe, whereas most types of priming are believed to arise from perceptual or semantic systems in the neocortex (Squire, 1994). The evidence for these theories includes reports that priming can be spared in amnesic individuals with medial-temporal lobe damage despite severely impaired recognition performance (e.g., Hamann \& Squire, 1997; Graf, Squire, \& Mandler, 1984; Warrington \& Weiskrantz, 1974). These findings are complemented by data from some individuals with occipital lobe damage, in whom recognition memory appears intact despite impaired (visual) priming (e.g., Gabrieli, Fleischman, Keane, Reminger, \& Morrell, 1995). Similar double dissociations have been reported in healthy individuals. For example, semantic processing of items affects recognition memory but can have little or no effect on priming, whereas repeating items across modalities typically affects priming but has little or no effect on recognition memory (for reviews, see Roediger \& McDermott, 1993; Richardson-Klavehn \& Bjork, 1988).

Some of these dissociations have been challenged, however: for example, with claims that amnesic patients 
do show impairments in repetition priming as well as recognition memory (Jernigan \& Ostergaard, 1993). More importantly, there are single-memory system theories that attribute the double dissociations to procedural differences between the typical recognition memory and priming tasks, which are unrelated to memory per se (e.g., Berry, Shanks, \& Henson, 2008; Buchner \& Wippich, 2000). One aim of the present study is to test whether there are qualitatively different patterns of brain activity associated with priming and recognition memory, which would be difficult to reconcile with such single-system accounts.

The debate is further complicated by the fact that, even if there are different memory systems, more than one may contribute to a given memory test. For example, repetition priming has been attributed to an increased "fluency" with which repeated items are processed (Jacoby \& Dallas, 1981), such as faster visual identification or facilitated semantic access. Importantly, the same increase in fluency can occur during recognition memory tests. Indeed, if participants become aware of this fluency (even if they have no conscious memory for prior presentation of the stimulus), they may use this to inform their recognition judgment. In other words, if a test item seems to be processed more fluently than expected, participants may attribute this to a past exposure and therefore call the item "old" (Whittlesea \& Williams, 2000).
This idea that repetition priming and recognition memory may, under some conditions, be influenced by a common memory signal has received much recent interest. For example, amnesic patients appear to be able to use fluency to support their recognition judgments (Verfaellie \& Cermak, 1999; though see Conroy, Hopkins, \& Squire, 2005; Stark \& Squire, 2000). Moreover, healthy individuals can be "tricked" by unexpected fluency. In a pioneering study by Jacoby and Whitehouse (1989), participants performed a recognition memory test for words. However, the test items were immediately preceded by a prime that was either the same or a different word (see Figure 1 for a similar design). Because the duration of the prime was so short and participants were not instructed about its presence, participants were unlikely to be able to identify it. Nonetheless, the probability of a subsequent "old" judgment to the test cue was increased when it matched the prime, whether or not it corresponded to a studied word. This can be explained if participants (mis)attribute the prime-induced fluency associated with processing of the test cue to a prior exposure in the study phase. When the duration of the prime was lengthened and participants were informed about it, the bias reversed such that primed test cues were less likely to be called old, consistent with participants attributing fluency to the prime rather than to the study phase (although see also Higham \& Vokey, 2000; Joordens \& Merikle, 1992).
Figure 1. Schematic of experimental design.

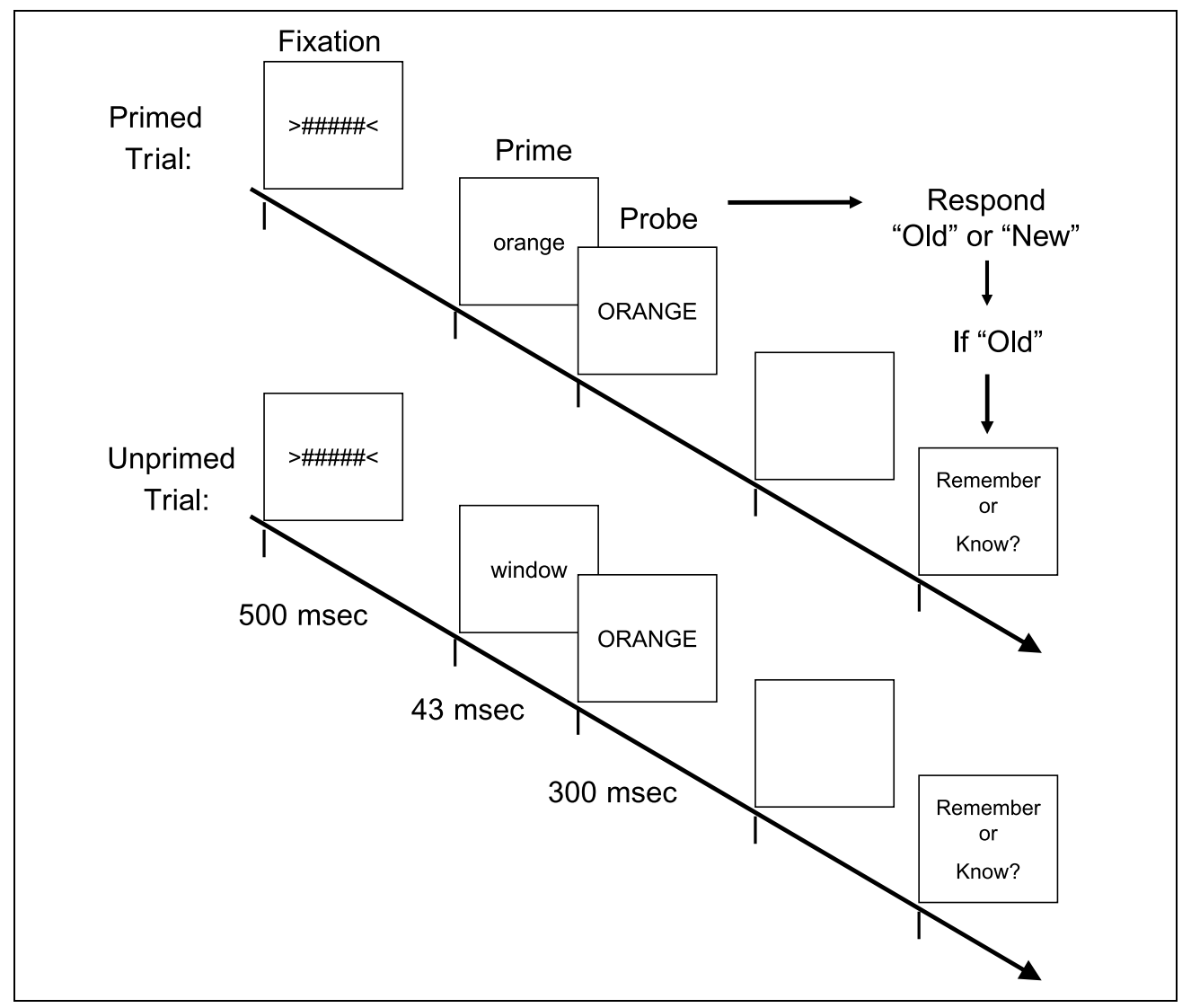


A subsequent experiment by Rajaram (1993, Experiment 3; see also Kinoshita, 1997) showed that this recognition bias induced by a masked prime affected only certain types of recognition judgment. Whenever participants made an "old" judgment, Rajaram asked them to indicate whether this judgment was based on details of the study episode (a "remember" response), or just a feeling of familiarity (a "know" response); a procedure introduced by Tulving (1985). The bias to respond "old" when test cues were primed by the same word was only found for those old judgments associated with a subsequent "know" response. In other words, when participants remembered specific details about the prior exposure of a word in the study phase (indicated by a remember response), they no longer seemed influenced by the fluency caused by the masked prime.

This pattern is consistent with dual-process models of recognition memory that distinguish between recollection and familiarity (Yonelinas, 2001; Mandler, 1980). Recollection refers to the retrieval of contextual aspects of the encoding episode (normally leading to a remember response), whereas familiarity refers to a conscious impression that an item has been experienced recently, in the absence of any contextual associations (normally leading to a know response). Several authors have suggested that familiarity and some types of priming share the same cause: Increased fluency at perceptual or conceptual stages of processing (Yonelinas, 2002; Whittlesea \& Williams, 2000; Wagner \& Gabrieli, 1998; Jacoby \& Dallas, 1981). According to this view therefore, at least one, but not all, of the factors contributing to recognition memory share an underlying cause with priming.

We investigated this issue further by combining Rajaram's (1993) recognition memory paradigm with electroencephalographic (EEG) recordings. More specifically, we wanted to see how the event-related potential (ERP) differences associated with priming of test cues compared with those associated with familiarity (as operationalized via know responses). A similar pattern of neural activity would support a common cause; a qualitatively different pattern of neural activity would suggest instead that familiarity and (masked) priming differ in the operation of at least one underlying memory system.

\section{METHODS}

\section{Participants}

Twenty-four undergraduate students (18 women) at Macquarie University gave written consent to participate in the study. All participants reported themselves to be in good health and normal or corrected-to-normal vision, with no history of neurological illness. Unfortunately, only data from 15 participants were recoverable from the storage media (13 women; 1 left-handed). One of these missed 18 of the 480 test trials.

\section{Materials}

Stimuli consisted of 480 words selected from the Medical Research Council (MRC) database described by Coltheart (1981). The selection criteria were that they were mediumfrequency words (30-70 occurrences per million based on the Kucera \& Francis, 1967, corpus), medium-to-high imageability (minimum 292 on the scale of 100-700 calculated by the MRC database by merging three sets of norms), and four to seven letters long. The words were divided into four sets matched on mean word length, mean frequency (38 per million), and mean imageability ratings (503). The assignment of the sets to the four experimental conditions resulting from a factorial combination of study status (old vs. new) and prime type (same vs. different) was counterbalanced across subjects such that for each subject an item appeared only once, and for every four subjects, each set appeared in each condition.

The words were presented centrally on the screen of a NEC Multisync 4FG monitor placed approximately $60 \mathrm{~cm}$ from the subject, who was comfortably seated in a padded chair and held a response pad. The display of stimulus materials and collection of responses were controlled by the DMASTR software developed by Forster and Forster (1990).

\section{Procedure}

Each experimental session consisted of four study-test blocks. In each block, the subject first studied a list of 60 sequentially presented words, then engaged in a recognition test where the 60 old words were mixed with 60 new items. In the test block, half of old words and half of new words were primed (i.e., preceded by the same word), and the other half were unprimed (i.e., preceded by a different word of the same study status, that is, re-paired with another word that occurred in the same block). Each study block also included two primacy and two recency filler items that were not included in the analysis; each test block was preceded by two practice items that were not included in the analysis.

Each study trial began with a fixation cue ("> \#\#\#\# \#\#\#<") presented for $500 \mathrm{msec}$ (see Figure 1). A word was then exposed for $300 \mathrm{msec}$ in place of the warning signal, followed by a blank screen for $1700 \mathrm{msec}$. Subjects were instructed to decide for each word whether it was relatively interesting, and to press a key marked "+" on the response pad if it was interesting, and a key marked "-" otherwise.

Each test trial began with the message "Press NEXT for next trial." Two hundred milliseconds after a subject's keypress, a forward mask which also served as a warning signal ("> \#\#\#\#\#\#<") was presented for 500 msec. At offset, it was immediately replaced by a prime, presented in lowercase letters, which was either the same or different from the target word (probe). Subjects were not informed of the presence of the prime 
word. The prime remained on the screen for three screen refresh cycles (43 msec), and was immediately replaced by the target word, presented in uppercase letters. The target remained on the screen for $300 \mathrm{msec}$. Subjects were instructed to press a key marked "+ " if the word had been presented during the study phase, and to press the "- " key otherwise, as soon as they could while avoiding errors. If the subject pressed the "- " key, the trial was finished, and the next trial began. If the subject pressed the "+" key, the message "Remember $(+)$ or Know (-)?" appeared, and remained on the screen until subject pressed either the "+" or "-" key, after which the trial was finished. In all cases, the "+ " key was assigned to the participant's dominant hand.

\section{EEG Acquisition}

EEG and electrooculogram (EOG) recordings were sampled continuously during the test phase at $5 \mathrm{msec} / \mathrm{channel}$ using NeuroScan software running on a 486 PC. EEG was recorded from 21 scalp electrodes $(\mathrm{FPz}, \mathrm{Fz}, \mathrm{Cz}, \mathrm{Pz}, \mathrm{Oz}$, FP1, F3, F7, C3, P3, T3, T5, O1, FP2, F4, F8, C4, P4, T4, T6, O2) according to the 10-20 system using an electrode cap produced by Electro-Cap International. Impedances were less than $5 \mathrm{k} \Omega$. Vertical and horizontal EOG (VEOG and HEOG, respectively) were recorded via electrodes situated above and below the left eye and on the outer canthi of each eye, respectively. EOG and EEG were amplified using a Grass Neurodata (Model 12) system with a band pass of $0.01-30 \mathrm{~Hz}$ ( $-6 \mathrm{~dB}$ down). All EEG electrodes were referred to linked mastoids.

\section{ERP Preprocessing}

Preprocessing was automated using EEG functions from SPM (www.fil.ion.ucl.ac.uk/spm); statistical analysis was performed using additional code written by the last author in Matlab (The Mathworks, www.mathworks.com/ products/matlab). In order to correct for artifacts caused by blinks, the continuous data were first searched for blinks, as defined by VEOG deflections exceeding $200 \mu \mathrm{V}$ and with a full-width-at-half-maximum determined by inspecting blinks from individual participants (between 200 and $400 \mathrm{msec}$ ). Blinks occurring during the 1000-msec epoch period were not used in the blink estimation procedure in order to minimize the risk of the VEOG channel including contributions from stimulus-locked brain activity (mean number of blinks remaining $=148$; range $=$ 40-529). A 50-100 msec window (again determined for each participant) centered on the peak of each blink in the VEOG was then calculated for each channel, and these windowed data averaged over all blinks. A correction weight for each EEG channel was then defined as the parameter estimate of a linear regression of the sig- nal in that time window relative to that for the VEOG channel (Picton et al., 2000). The continuous data for each EEG channel were corrected by subtracting the continuous VEOG data multiplied by the corresponding correction weight. In other words, the estimated distribution of blink-related EEG effects during the interepoch periods was used to remove blink artifacts from the epoch of interest.

The continuous data were then epoched from $-100 \mathrm{msec}$ to +900 msec relative to the onset of the prime, and baseline-corrected relative to the $100-\mathrm{msec}$ prestimulus period. Epochs in which the amplitude of any of the EEG or HEOG channels exceeded $120 \mu \mathrm{V}$ were rejected (mean number of rejects $=27$; range $=0-91$ ). The data were then resynchronized with the target (i.e., $t=0$ is target onset, from -143 to $+857 \mathrm{msec}$ ).

Scalp potential maps were created by linear interpolation. Differences in scalp topographies were tested by ANOVAs over all sites, after normalizing amplitude differences to the mean min-max range over sites and participants (McCarthy \& Wood, 1985); a linear scaling method that does not to suffer from the problems of vector scaling described by Urbach and Kutas (2002).

\section{Basic Analysis Strategy}

The behavioral and ERP data were analyzed using repeated measures analyses of variance (ANOVAs). Significant effects are only reported in the absence of significant higher-order interactions. All follow-up $t$ tests were two-tailed.

For recognition accuracy, a 2 (studied/unstudied) $\times 2$ (response type: $\mathrm{R} / \mathrm{K}) \times 2$ (primed/unprimed) ANOVA was performed on percentage of responses to assess the effect of priming. Due to insufficient numbers of responses (i.e., more than 10 for each participant) in some cells of the full factorial design (e.g., $\mathrm{R}$ and $\mathrm{K}$ false alarms, or when splitting misses into primed and unprimed), the median reaction times (RTs) and the ERP data were analyzed in two partitioned ANOVAs instead: The first employed a single four-level condition factor involving the conditions of remember hits (R hits), know hits (K), misses and correct rejection (CRs), collapsed across priming condition, and served to test replication of previously established ERP memory effects (e.g., the "FN400" and "parietal old-new" effects). The second ANOVA employed two factors that crossed priming condition (primed/unprimed) with response ( $\mathrm{R}$ hit, $\mathrm{K}$ hit, and $\mathrm{CR}$ ).

In the ERP ANOVAs, the factors were supplemented by a third factor with 21 levels, one per scalp site (excluding the reference), performed on the mean amplitude across various time windows of interest (see Results). All analyses used a Greenhouse-Geisser correction for nonsphericity. Significance was determined using an alpha value of .05 . 


\section{RESULTS}

\section{Behavioral Results}

The percentage of responses to each condition and associated RTs are shown in Tables 1 and 2, respectively. There were too few false alarms to estimate RTs reliably, hence, these do not appear in Table 2. Overall accuracy was $\operatorname{Pr}(\mathrm{Ht}-\mathrm{FA})=.51$ for $\mathrm{R}$ judgments, and $\operatorname{Pr}=.10$ for $\mathrm{K}$ judgments, both of which were reliably greater than 0 , $t(14)>3.39, p<.005$, indicating that $\mathrm{K}$ judgments were more than guesses.

For "old" judgments, a 2 (studied/unstudied) $\times 2(\mathrm{R} /$ $\mathrm{K}) \times 2$ (primed/unprimed) ANOVA showed a reliable interaction between $\mathrm{R} / \mathrm{K}$ and priming $[F(1,14)=6.39$, $p=.024]$, and a trend for an interaction between study status and priming $[F(1,14)=4.12, p=.062]$. When examining $\mathrm{R}$ and $\mathrm{K}$ judgments separately, there were no main effects of priming or interactions between priming and study status for $\mathrm{R}$ judgments $(p s>.45)$, but there was a reliable main effect of priming in increasing the percentage of $\mathrm{K}$ judgments $[F(1,14)=10.1, p=$ $.007]$. Despite the numerical trend for a greater primingrelated increase in $\mathrm{K}$ judgments to unstudied items (false alarms) than to studied items (hits), the interaction between priming and study status for $\mathrm{K}$ judgments did not reach significance $[F(1,14)=2.20, p=.16]$.

In line with the ERP analyses reported below, ANOVAs were performed on RTs (to the first old-new judgment) for: (1) R hits, K hits, misses, and CRs, collapsed across primed vs. unprimed, and (2) R hits, K hits, and CRs, split by primed vs. unprimed (see Methods). The first $1 \times$ 4 ANOVA revealed a highly significant main effect of condition $[F(2.06,28.8)=11.9, p<.001]$. As can be

Table 1. Mean Percentage of Responses for Each Condition (Studied/Unstudied $\times$ Primed/Unprimed) with Response Category and Range in Brackets $(n=120$ per Condition, i.e., Column)

\begin{tabular}{|c|c|c|c|c|}
\hline \multirow[b]{3}{*}{ Response } & \multicolumn{4}{|c|}{ Condition, \% $(n=120)$} \\
\hline & \multicolumn{2}{|c|}{ Studied } & \multicolumn{2}{|c|}{ Unstudied } \\
\hline & Primed & Unprimed & Primed & Unprimed \\
\hline \multirow[t]{3}{*}{$\mathrm{R}$} & (Hit) & (Hit) & (FA) & (FA) \\
\hline & 51.8 & 53.2 & 1.7 & 1.6 \\
\hline & $(24-84)$ & $(28-86)$ & $(0-6)$ & $(0-6)$ \\
\hline \multirow[t]{3}{*}{$\mathrm{K}$} & (Hit) & (Hit) & (FA) & (FA) \\
\hline & 27.4 & 25.6 & 19.4 & 13.5 \\
\hline & $(12-50)$ & $(8-40)$ & $(2-34)$ & $(2-30)$ \\
\hline \multirow[t]{3}{*}{ (New) } & (Miss) & (Miss) & $(\mathrm{CR})$ & (CR) \\
\hline & 20.8 & 21.2 & 78.9 & 84.7 \\
\hline & $(4-38)$ & $(6-38)$ & $(62-98)$ & $(66-98)$ \\
\hline
\end{tabular}

$\mathrm{FA}=$ false alarm; $\mathrm{CR}=$ correct rejection.
Table 2. Mean of Median of RTs to Make First "Old-New" Decision for Each Condition

\begin{tabular}{|c|c|c|c|c|}
\hline & \multicolumn{2}{|c|}{ Studied } & \multicolumn{2}{|c|}{ Unstudied } \\
\hline & Primed & Unprimed & Primed & Unprimed \\
\hline \multirow[t]{3}{*}{$\mathrm{R}$} & (Hit) & (Hit) & - & - \\
\hline & 788 & 806 & & \\
\hline & (178) & (156) & & \\
\hline \multirow[t]{3}{*}{ K } & (Hit) & (Hit) & - & - \\
\hline & 964 & 1031 & & \\
\hline & (280) & (299) & & \\
\hline \multirow[t]{3}{*}{ (New) } & (Miss) & (Miss) & (CR) & (CR) \\
\hline & 1031 & 1009 & 896 & 899 \\
\hline & (248) & $(260)$ & (131) & (142) \\
\hline
\end{tabular}

$S D$ values are presented in parentheses; $-=$ insufficient numbers.

seen in Table 2, this reflected the fact that "old" judgments to studied items that were subsequently indicated as remembered were significantly faster than all other conditions $[t(14)>3.54, p s<.005]$. CRs were significantly faster than misses $[t(14)=3.12, p=.007]$, although not necessarily $\mathrm{K}$ hits $[t(14)=1.77, p=.098]$, whereas the RTs to the latter two conditions did not differ $[t(14)=0.51, p=.62]$.

The second $2 \times 3$ ANOVA on RTs showed a reliable main effect of priming, with faster RTs for primed items $[F(1,14)=6.35, p=.024]$ (as well as a main effect of condition, as expected from the above ANOVA), but no interaction with condition $[F(1.29,18.0)=2.43, p=.13]$. Given that priming might be expected to affect correct "old" and correct "new" judgments differently (despite the lack of a reliable interaction) - that is, speed up "old" judgments but slow down "new" judgmentspost hoc one-tailed $t$ tests were performed for each condition separately: Priming produced faster "old" judgments for both $\mathrm{R}$ hits and $\mathrm{K}$ hits $[t(14)>1.96$, ps < $.05]$, but had no reliable affect on CRs $[t(14)=0.29$, $p=.39]$.

\section{ERP Results}

The first analysis collapsed across primed-unprimed trials, in order to compare the ERP differences between $\mathrm{R}$ hits and $\mathrm{K}$ hits, and between hits, misses, and CRs, which have been reported several times previously. For this analysis of "basic memory" effects, the a priori time windows of 300-500 and 500-800 msec were taken from Rugg et al. (1998), and are fairly standard for the "FN400" and "parietal old-new" effects, respectively. More specifically, we sought to isolate the neural correlates of familiarity by contrasting $\mathrm{K}$ hits with misses, a contrast in which items are studied in both cases but only recognized 
in the former case (Duarte, Ranganath, Winward, Hayward, \& Knight, 2004).

\section{Analysis of Basic Memory Effects}

The mean and range of the number of artifact-free epochs per condition were: $\mathrm{R}$ hits (mean $=120$, range $=$ 61-187), $\mathrm{K}$ hits (mean $=59$, range $=20-110)$, misses $($ mean $=48$, range $=15-90)$, and CRs $($ mean $=185$, range $=145-232$ ). The corresponding ERPs are shown for selected sites in Figure 2.

300-500 msec window ("FN400" effect). The omnibus 4 (condition) $\times 21$ (channel) ANOVA showed a significant Condition $\times$ Channel interaction $[F(5.42,75.9)=$ $3.54, p=.005]$. The follow-up ANOVA contrasting only $\mathrm{R}$ hits and $\mathrm{K}$ hits showed no reliable condition effects $\left(F_{\mathrm{S}}<1.455, p s>.24\right)$. The follow-up ANOVA contrasting $\mathrm{K}$ hits and misses, however, showed a reliable Condition $\times$ Channel interaction $[F(3.21,44.9)=2.89, p=$ $.043]$, as did the ANOVA contrasting misses and CRs $[F(2.48,34.7)=5.12, p=.007]$.
The topography of the difference between $\mathrm{K}$ hits and misses had a frontal distribution that was more positivegoing for $\mathrm{K}$ hits over right frontal channels (Figure $3 \mathrm{~A}$ ). The mean amplitude for channel Fz showed a basic pattern of hits being more positive-going than misses or CRs. The topography of the difference between misses and CRs had a more posterior distribution that was more positive-going for misses over occipital channels (Figure 3B). The mean amplitude for channel Oz showed a basic pattern of studied items being more positive-going than unstudied items. These two topographies differed reliably $[F(2.56,35.9)=4.08, p=.018]$, replicating the findings of Rugg et al. (1998). For shorthand, we will refer to the latter difference between misses and CRs as a "long-lag priming" effect from the study phase, as distinct from the "masked priming" manipulation during the test phase (see Discussion).

500-800 msec window ("parietal old-new" effect). The omnibus 4 (condition) $\times 21$ (channel) ANOVA showed a significant Condition $\times$ Channel interaction $[F(5.43,76.1)=3.37, p=.007]$. The follow-up ANOVA
Figure 2. ERP data from selected midline channels (Fz, $\mathrm{Pz}, \mathrm{Cz}$, and $\mathrm{Oz}$ ) for remember hits (R hits), know hits (K hits), misses, and CRs. Time $0 \mathrm{msec}=$ probe onset; gray vertical lines indicate extents of time windows of interest: 300-500 and 500-800 msec. Note: VEOG channel amplitude scaled by $1 / 20$, and all data low-pass filtered $(20 \mathrm{~Hz})$ for display purposes

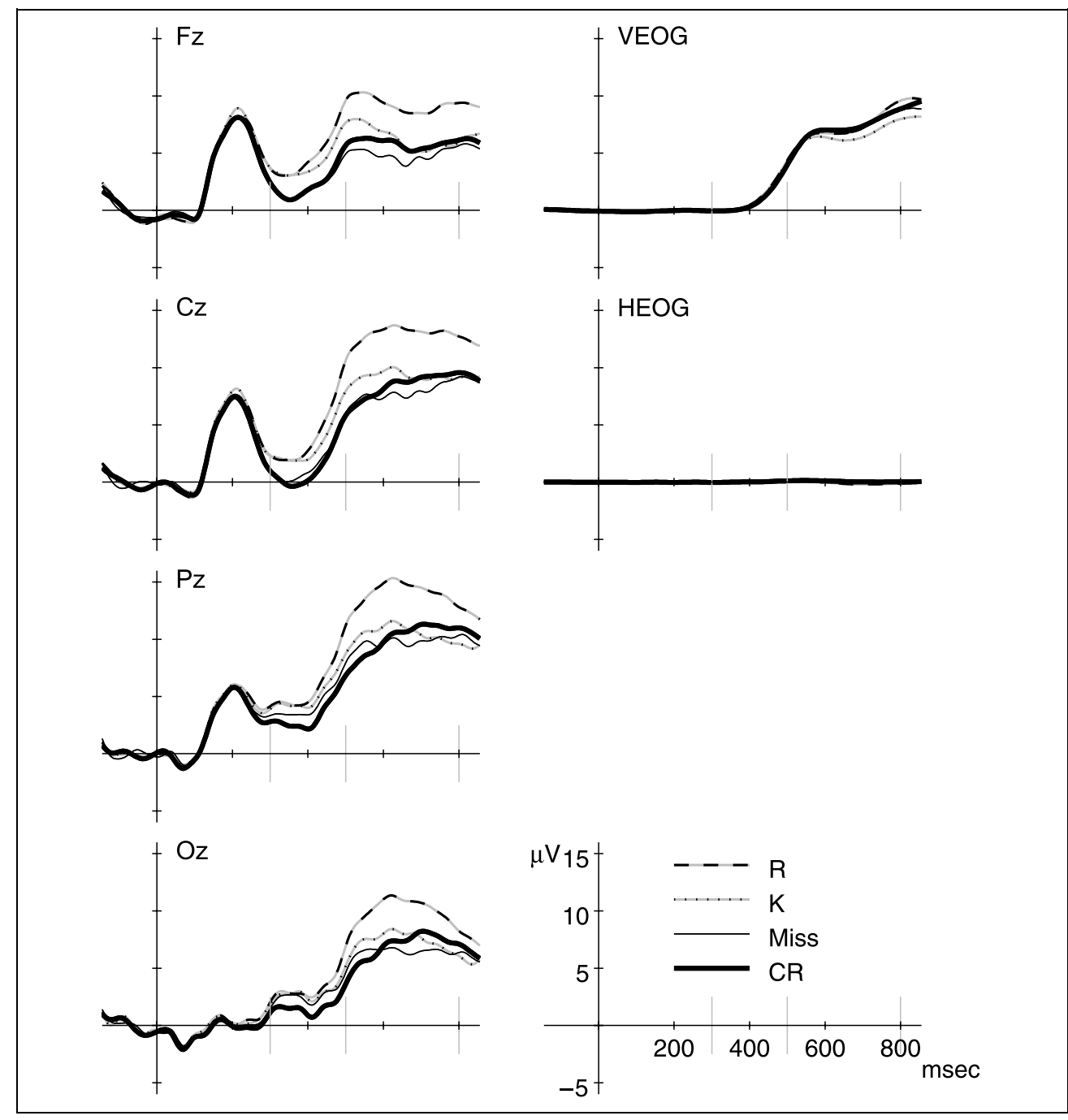


Figure 3. Topographies (mean difference) and amplitudes (mean \pm standard error) at peak channels for time windows of interest in the analysis of basic memory effects. All units are in microvolts $(\mu \mathrm{V})$.
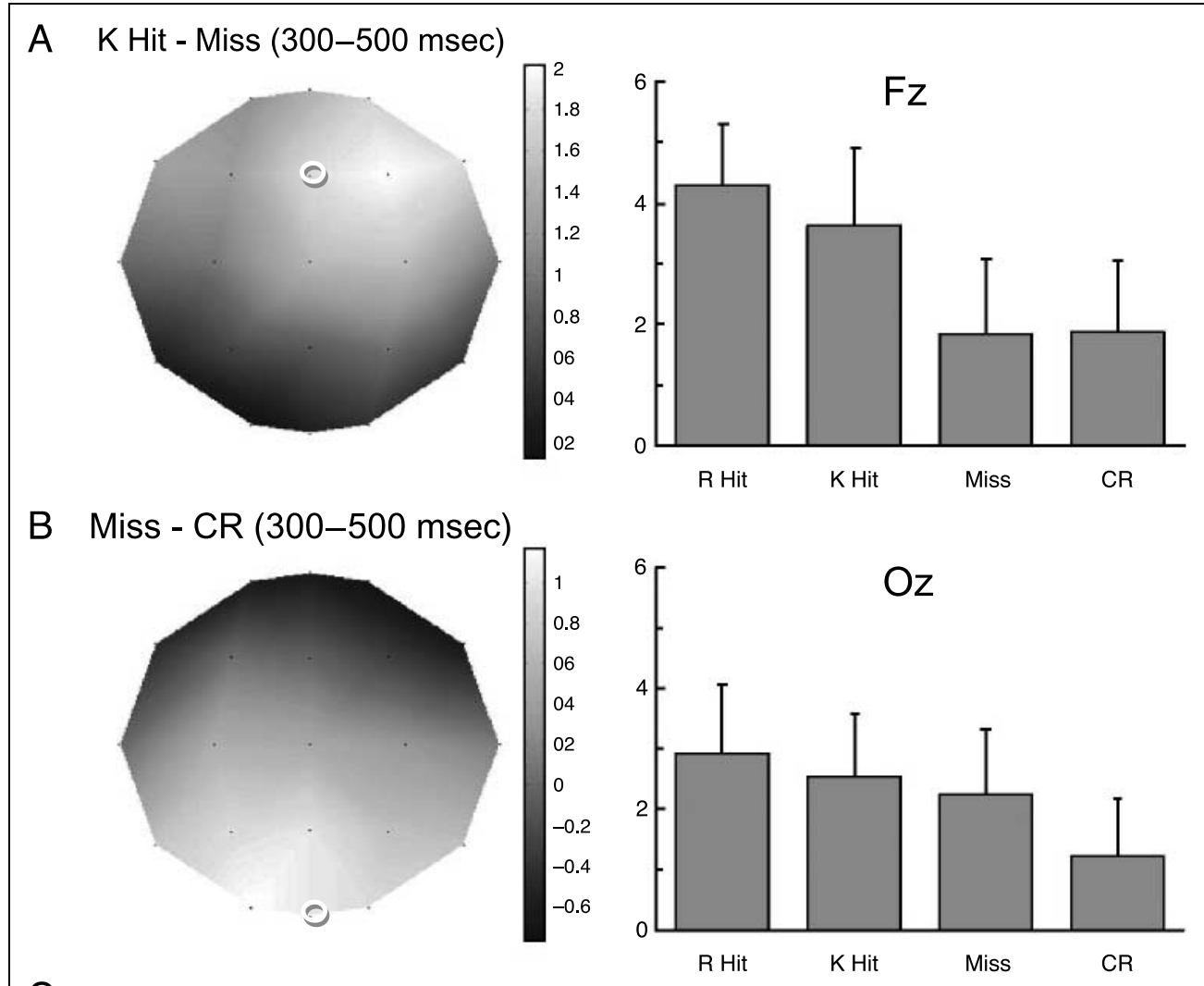

C R Hit - K Hit (500-800 msec)
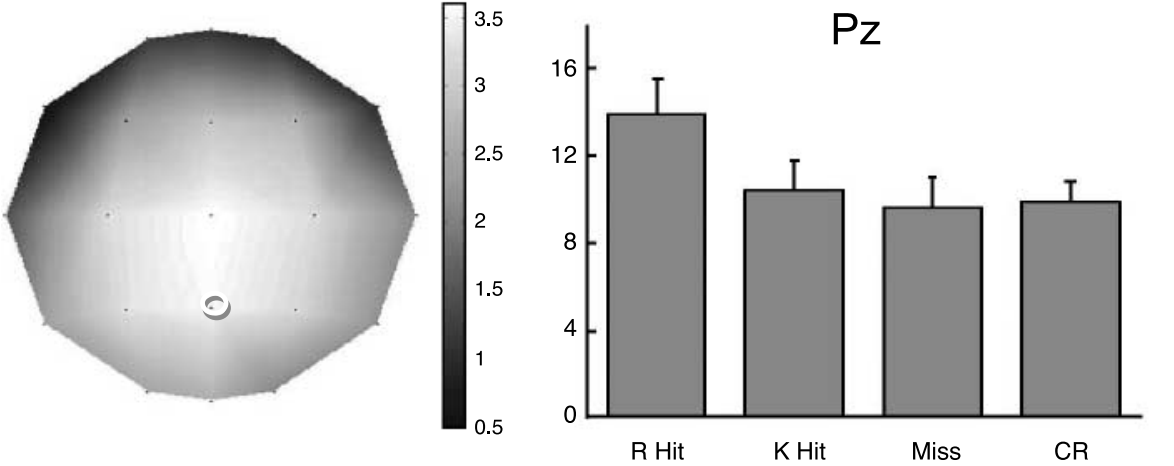

contrasting $\mathrm{R}$ hits and $\mathrm{K}$ hits showed a reliable Condition $\times$ Channel interaction $[F(4.27,59.8)=5.47, p<.001]$. Neither the ANOVA contrasting $\mathrm{K}$ hits and misses, nor that contrasting misses and CRs, showed a reliable Condition $\times$ Channel interaction or main effect, $p s>.13$.

The topography of the difference between $\mathrm{R}$ hits and $\mathrm{K}$ hits had a parieto-central distribution that was more positive-going for R hits (Figure 3C). The mean amplitude for channel $\mathrm{Pz}$ showed a basic pattern of $\mathrm{R}$ hits being more positive-going than all other conditions, consistent with a number of previous studies associating this parietal old-new effect with attention to recollected information (Herron \& Rugg, 2003). The topography of this effect differed reliably from that of the earlier FN400 difference between $\mathrm{K}$ hits and misses $[F(4.23,59.16)=$ $3.51, p=.01]$, although any difference in its topography from that of the earlier long-lag priming effect, that is, difference between misses and CRs, failed to reach significance $[F(3.57,49.9)=1.85, p=.14]$.

\section{Analysis of Masked Priming Effects}

For the analysis of masked priming effects, the ERPs for $\mathrm{R}$ hits, $\mathrm{K}$ hits, and CRs were broken down by primed vs. unprimed. One participant was removed for having fewer than 10 artifact-free trials for one of the six conditions (unprimed K hits). For the remaining 14 subjects, the mean and range of number of artifact-free trials were: primed R hits 58 (28-99), primed K hits 32 (15-61), primed CRs 89 (71-117), unprimed R hits 58 (33-88), unprimed K hits 31 (16-49), unprimed CRs 95 (73-115). The ERPs for selected sites are shown in Figure 4. 


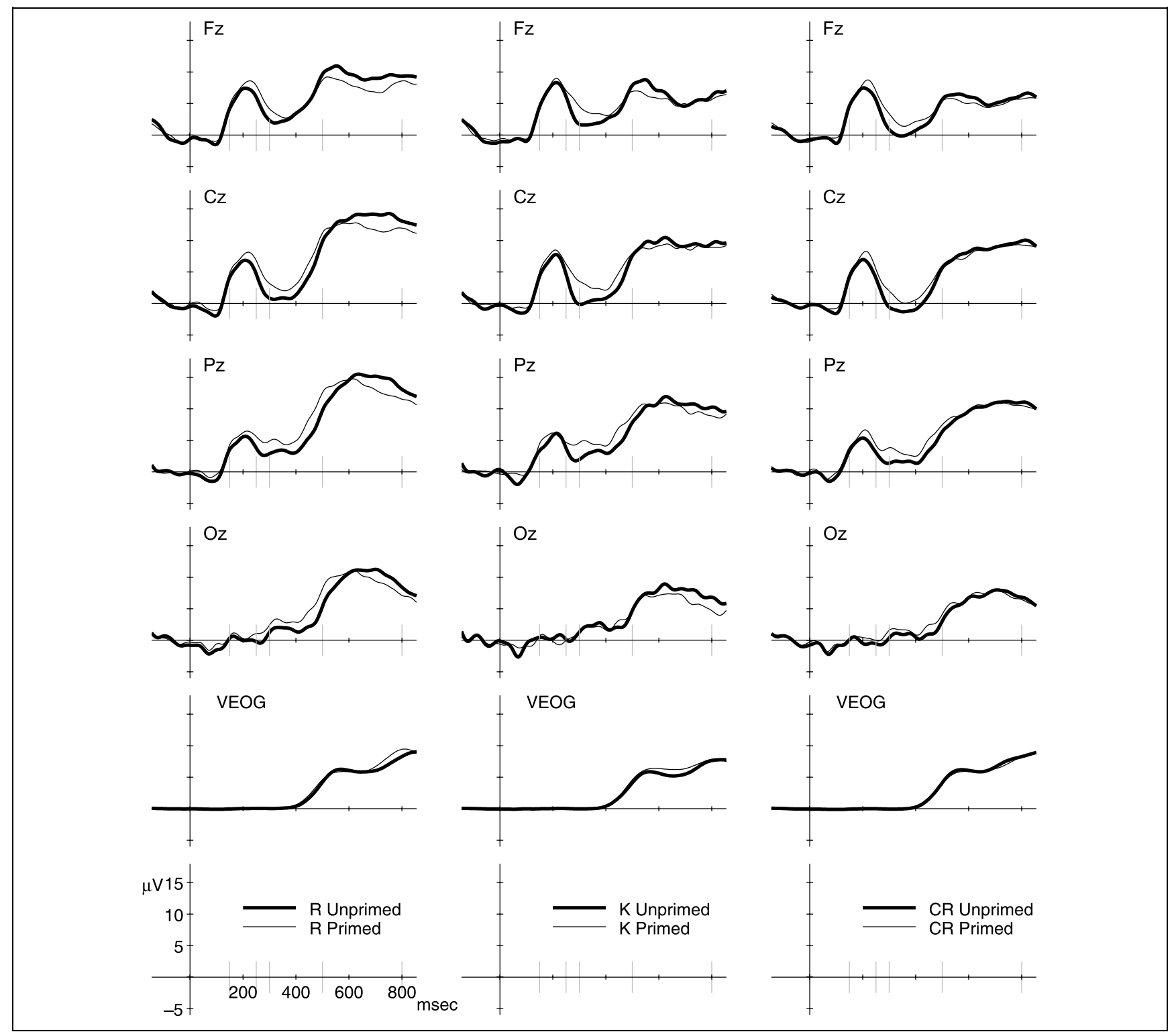

Figure 4. ERP data from selected midline channels ( $\mathrm{Fz}, \mathrm{Cz}, \mathrm{Pz}$, and $\mathrm{Oz}$ ) for remember hits ( $\mathrm{R}$ hits), know hits (K hits), and CRs that were either primed or unprimed. Time $0 \mathrm{msec}=$ probe onset; gray vertical lines indicate extents of time windows of interest: 150-250, 300-500, and 500-800 msec. Note: all data low-pass filtered $(20 \mathrm{~Hz})$ for display purposes. HEOG was virtually indistinguishable across conditions.

300-500 msec window ("FN400" effect). The omnibus 2 (primed/unprimed) $\times 3$ (response: $\mathrm{R} / \mathrm{K} / \mathrm{CR}) \times 21$ (channel) ANOVA showed reliable two-way interactions between priming and channels $[F(3.34,43.4)=3.87, p=$ $.013]$, and between response and channels $[F(6.46$, $84.0)=2.42, p=.029]$. The topography of the masked priming effect was a central positivity for primed relative to unprimed trials (Figure 5A). The mean amplitude for channel $\mathrm{Pz}$ showed greater amplitude for primed than unprimed trials across all response types ( $\mathrm{R}$ hits, $\mathrm{K}$ hits, CRs). Importantly, the topography of this primedunprimed difference was significantly different from that of the more frontal FN400 positivity for $\mathrm{K}$ hits versus misses in the previous analysis $[F(2.62,34.0)=3.25, p=$ .039; cf. Figure 3A]. There was also a trend for a qualita- tively different topography from that of the more occipital positivity of the "long-lag" priming effect of misses versus CRs [cf. Figure 3B; $F(3.63,47.2)=2.23, p=.08$ ].

A follow-up $2 \times 2$ ANOVA for only $\mathrm{R}$ hits and $\mathrm{K}$ hits showed a reliable two-way interaction between channels and priming $[F(2.84,36.9)=3.07, p=.042]$, and a threeway interaction between channels, response, and priming that approached significance $[F(2.00,25.9)=3.08, p=$ .063]. The latter appeared to reflect a greater effect of priming on $\mathrm{R}$ hits than $\mathrm{K}$ hits (see, e.g., Figure $5 \mathrm{~A}$ ), and may reflect a contribution of the later parietal effect, which appeared to onset earlier for primed than unprimed trials (see Figure 4 and Latency Analysis below). Nonetheless, priming exerted reliable effects on both $\mathrm{R}$ hits and $\mathrm{K}$ hits when tested separately, $p s<.02$. 


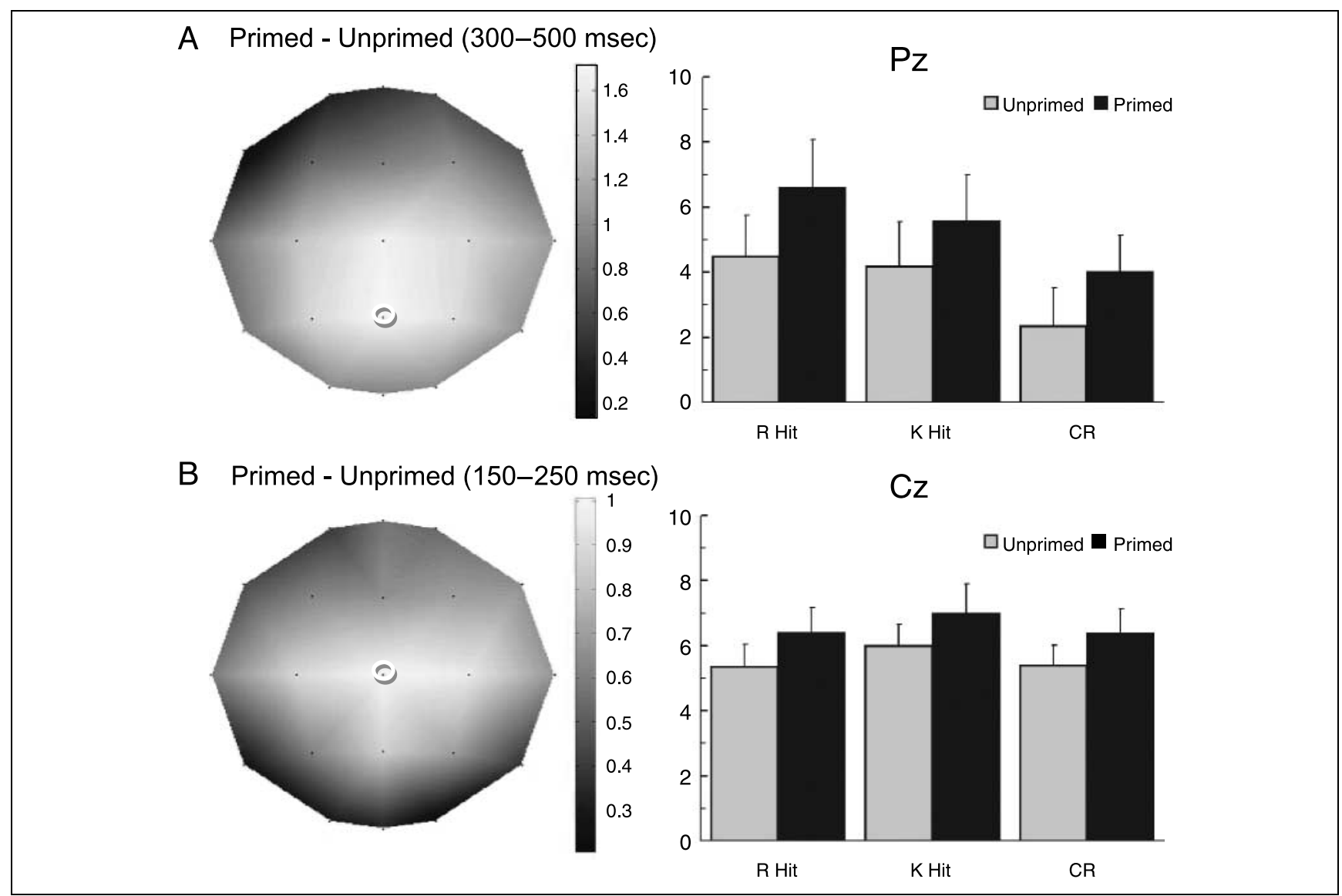

Figure 5. Topographies (mean difference) and amplitudes (mean \pm standard error) at peak channels for time windows of interest in the analysis of masked priming effects.

The follow-up $2 \times 2$ ANOVA for $\mathrm{K}$ hits and CRs only showed a main effect of priming $[F(1.00,13.0)=15.47$, $p=.002]$, and a Response $\times$ Channel interaction $[F(4.89$, 63.6) $=2.49, p=.042]$, but no Priming $\times$ Response interactions.

500-800 msec window ("parietal old-new" effect). The omnibus 2 (primed/unprimed) $\times 3$ (response: $\mathrm{R} / \mathrm{K} / \mathrm{CR}) \times$ 21 (channel) ANOVA showed only a reliable two-way interaction between response and channels $[F(5.24$, $68.1)=5.02, p<.001]$, but no reliable effects of priming $(p s>.12$ ). The follow-up $2 \times 2$ ANOVA for $\mathrm{R}$ hits and $\mathrm{K}$ hits confirmed only a reliable two-way interaction between channels and response $[F(4.17,54.2)=5.59$, $p<.001]$ (as expected from previous analyses). The follow-up $2 \times 2$ ANOVA for $\mathrm{K}$ hits and CR showed no reliable effects $(p s>.13)$.

150-250 msec window. Closer inspection of the waveforms in Figure 4 suggested that priming had an effect even earlier in the epoch, around the P200. A post hoc analysis was therefore performed on a $150-250 \mathrm{msec}$ time window. The omnibus 2 (primed/unprimed) $\times 3$ (response: $\mathrm{R} / \mathrm{K} / \mathrm{CR}) \times 21$ (channel) ANOVA showed a reliable main effect of priming $[F(1,13)=13.14, p=$
.003], but no other effects. The follow-up $2 \times 2$ ANOVAs for $\mathrm{R}$ hits and $\mathrm{K}$ hits, and for $\mathrm{K}$ hits versus CRs, showed similar main effects of priming in both cases $[F(1,13)>$ $6.73, p s<.05]$, although the latter also showed a main effect of $\mathrm{K}$ hits versus CRs that approached significance $[F(1,13)=4.36, p=.057]{ }^{1}$

The topography of this "early" masked priming effect was a central positivity, similar to its topography from 300 to 500 msec (Figure 5B), and again with an amplitude at $\mathrm{Cz}$ that was more positive for primed trials across all response categories. Interestingly, the topography of the early masked priming effect differed reliably from that of the later long-lag priming effect [i.e., misses vs. CRs from 300 to $500 \mathrm{msec} ; F(3.58,46.5)=4.04$, $p=.009$ ], although there was no evidence that it (unlike the 300-500 msec masked priming effect) differed from the subsequent FN400 [i.e., K hits vs. misses from 300 to 500 msec; $F(2.73,35.5)=0.82, p=.48]$.

\section{Latency Analysis of Priming Effects}

Closer inspection of the waveforms also suggests that priming may affect the latency of ERP responses. For example, inspection of $\mathrm{Pz}$ (Figure 4) suggests that the $\mathrm{P} 600$ peak occurs earlier for primed than unprimed trials. To 
test this, differences between response categories were binned every $25 \mathrm{msec}$ for primed and unprimed conditions. The onset of a differential response was then defined as the first time bin of at least three successive time bins, in which there was either a main effect of response category or a Response $\times$ Channel interaction that survived at $p<.025$ (given two effects tested at each time bin). For the comparison of $\mathrm{R}$ hits versus $\mathrm{K}$ hits, the earliest differential response was $525 \mathrm{msec}$ for the unprimed condition and $475 \mathrm{msec}$ for the primed condition. This differential response remained significant until the end of the epoch in both cases (Figure 6A), making it unclear whether the effect of priming on the $\mathrm{R}-\mathrm{K}$ effect reflects a true shift in latency or instead an increase in duration. One reason for an increase in duration of an ERP effect is a higher variability in the latency of that effect across trials or participants. Thus, priming might decrease the latency of the P600 (Figure 4), but the variance of this decrease might be higher for trials with $\mathrm{R}$ judgments than for those with $\mathrm{K}$ judgments.

For the comparison of $\mathrm{K}$ hits versus CRs (given that there were insufficient trials to split misses by primed and unprimed), the earliest differential response was $300 \mathrm{msec}$ for both unprimed and primed conditions (and
Figure 6. ERP difference waves for (A) unprimed $\mathrm{R}$ hits versus unprimed $\mathrm{K}$ hits (dark line) and primed $\mathrm{R}$ hits versus primed $\mathrm{K}$ hits (faint line), and (B) unprimed $\mathrm{K}$ hits versus unprimed CRs (dark line) and primed $\mathrm{K}$ hits versus primed CRs (faint line). Time $0 \mathrm{msec}=$ probe onset; gray vertical lines indicate extents of time windows of interest: 150-250, 300-500, and 500-800 msec. Note: all data low-pass filtered $(20 \mathrm{~Hz})$ for display purposes.

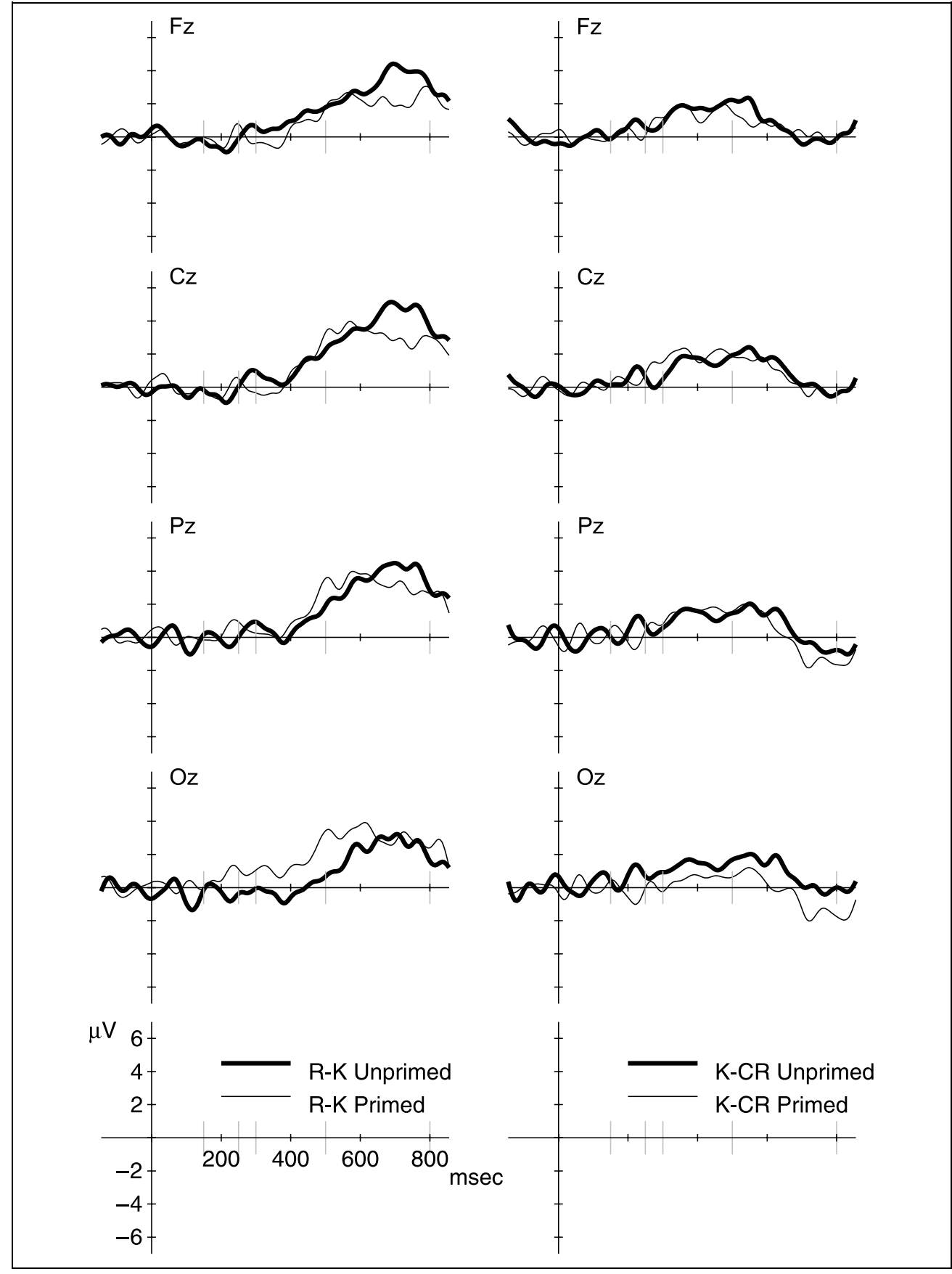


the difference ceased to be reliable after $525 \mathrm{msec}$ or 550 msec, respectively). Thus, priming did not appear to affect appreciably the onset or duration of the $\mathrm{K}$ hit CR difference (Figure 6B).

\section{DISCUSSION}

The main aim of the present study was to compare the neural correlates of the familiarity signal assumed to contribute to recognition memory with the neural correlates of a fluency effect induced by masked priming of test cues. Consistent with prior studies (Kinoshita, 1997; Rajaram, 1993), our priming manipulation increased the incidence of know responses, but not remember responses, for both studied and unstudied items. This is consistent with the hypothesis that, in the absence of recollection, the feeling of familiarity induced by more fluent processing of a primed test cue may be falsely attributed to the prior study episode. Assuming that participants were not aware of the true source of the fluency (i.e., the primes), this hypothesis is consistent with attribution theory (Whittlesea \& Williams, 2000; Jacoby \& Whitehouse, 1989). ${ }^{2}$

The ERP results showed, on the other hand, that the neural correlates of the familiarity effect, as operationalized by the difference between correct know judgments (K hits) and incorrect new judgments (misses), were qualitatively different from the neural correlates of the masked priming effect: From 300 to $500 \mathrm{msec}$ poststimulus, the former "FN400" effect had a more frontal topography than the latter. This suggests that familiarity, at least as operationalized in the present recognition memory test, derived from sources different from, or in addition to, the fluency induced by masked priming of test cues. This is consistent with multiple-memory system theories (or at least, is difficult to reconcile with some single-system theories that attribute familiarity and priming to a common memory signal, e.g., Berry et al., 2008).

Furthermore, there were a number of other striking findings in the present data, including one of the few replications of a longer-term repetition effect (from the study phase), as operationalized by misses versus CRs, that differed qualitatively from both the familiarity effect and the masked priming effect. We revisit these findings first, in relation to previous ERP studies, before attempting to relate the data to current models of recognition memory.

\section{Repetition Effects from the Study Phase}

In addition to the novel ERP effect associated with masked priming of test cues (in the context of a recognition memory test), the present data showed simultaneous replication of three other memory effects that have been reported previously, most notably by the study of Rugg et al. (1998). One of these, the "parietal old-new effect" from 500 to $800 \mathrm{msec}$, has been reported many times, and is believed to reflect the representation of, or attentional orientation toward, information recollected from the study episode (see, e.g., Vilberg, Moosavi, \& Rugg, 2006; Wilding, 2000). This is consistent with the higher amplitude found here for studied items given a remember response ( $\mathrm{R}$ hits) than for any other response category, namely, studied items given a know response (K hit) or a new response (miss), or for unstudied items given a new response (CRs), none of which differed reliably in this 500-800 msec time window (Figure 3C; see also Duarte et al., 2004; Smith, 1993).

The "FN400" or "mid-frontal old-new effect" that occurred earlier from 300 to $500 \mathrm{msec}$ has also been shown several times before (see, e.g., Curran, 2000; Rugg et al., 1998) and has been associated with the familiarity signal described by dual-process models (although this is a matter of current debate; see Paller, Voss, \& Boehm, 2007; Rugg \& Curran, 2007). This proposal is consistent with the present finding of higher amplitude for studied items judged "old," regardless of whether remembered or known (i.e., $\mathrm{R}$ hits and $\mathrm{K}$ hits), than for items judged "new" (i.e., misses or CRs; Figure 3A). Consistent with previous findings (Duarte et al., 2004), the topography of this FN400 effect (as operationalized by K hits vs. misses) differed reliably from that of the parietal oldnew effect (as operationalized by $\mathrm{R}$ hits vs. K hits), suggesting different underlying neural generators (Rugg \& Coles, 1995).

A third effect reported here was the difference between studied and unstudied items that were both judged "new" (i.e., misses vs. CRs), which was found between 300 and 500 msec with an occipital-positive topography that differed reliably from that of the "FN400" effect in the same time window (Figure 3B). Although originally reported by Rugg et al. (1998), this effect has not been found often (although see Friedman, 2005). Because their effect was not expressed in conscious recognition judgments, and because it was also found in conjunction with priming for repeated items in a semantic judgment task, Rugg et al. attributed this effect to a form of implicit memory and related it to priming. Of particular interest is the present finding that the topography of this "occipital long-lag priming" effect differed reliably from that of the fourth memory effect demonstrated here, namely, the "masked repetition priming" effect (at least from 150 to $250 \mathrm{msec}$ ), suggesting that these two effects reflect different neural systems (e.g., possibly different types of fluency; see below).

\section{Masked Priming in the Test Phase}

The effect of masked priming of test cues was more complex than the memory effects described above. A main effect of priming (primed $>$ unprimed) was found in an early time window that encompassed the P200 
(150-250 msec), maximal on central electrodes, that appeared to apply to all response types ( $\mathrm{R}$ hits, $\mathrm{K}$ hits, and CRs; Figure 5B). This masked priming effect persisted, with similar topography, into the 300-500 msec time window (but not 500-800 msec), when it appeared additive with the FN400 effect. In this time window, there was a trend for an interaction between priming and recollection (as operationalized by R hits vs. K hits), although this appeared to be driven by an earlier onset of the parietal old-new effect for primed relative to unprimed test cues (see below for further discussion). The topography of the masked priming effect differed reliably (in at least one of the 150 250 and 300-500 msec time windows) from both the FN400 effect and the occipital long-lag priming effect.

Although this masked repetition priming effect has not previously been dissociated from the other memory effects described here, it is not unprecedented. A study by Schnyer, Allen, and Forster (1997, Experiment 1) also examined masked word priming within a standard recognition memory task, although the prime-probe SOA (2500 msec) was much longer, and filled with an intervening word. These authors found a positive modulation for primed words between 400 and $800 \mathrm{msec}$, with a centro-parietal distribution similar to here (though stronger on the left). There was no evidence of an earlier effect however (possibly because of the longer SOA). A second study, by Holcomb and Grainger (2006), used a procedure closer to the present one, although in the context of an indirect memory task (semantic target detection). They did find an earlier masked priming effect, in the form of a negative-going deflection between 175 and $300 \mathrm{msec}$ that was greater when prime and probe words differed than when they were the same (i.e., a positive difference for primed minus unprimed, as here), with a fronto-central distribution not that dissimilar from that found here. Because a third condition in which prime and probe had partially overlapping letters produced a deflection of intermediate amplitude, these authors suggested that the effect might occur at the level of bigrams or trigrams of letters. Later effects of masked repetition were also found, one peaking at 450 msec that was again less negative-going for their "primed" condition relative to their "unprimed" condition, and with a central-parietal distribution, similar to that in Figure 5A. They related this later effect to a modulation of the N400 (see below).

\section{Theoretical Interpretation of ERP Effects}

The dissociation between the FN400 and parietal old-new effect is broadly consistent with dual-process models of recognition memory, with the latter reflecting recollection and the former familiarity (Mandler, 1980). The third memory effect-the long-lag priming effect operationalized by misses versus CRs-might instead reflect longerterm perceptual fluency. For example, some words may not have undergone extensive semantic elaboration dur- ing our study phase, resulting in them not being recognized at test. Nonetheless, visual overlap between the study and test items may cause some fluency when rereading the words at test, consistent with the more occipital focus of the effect (Figure 3B). This hypothesis is also consistent with the claim that perceptual fluency does not contribute much to recognition memory under normal circumstances (Poldrack \& Logan, 1998; Wagner \& Gabrieli, 1998). It is further consistent with the analogous ERP effect that Rugg et al. (1998; Experiments 3-4) found in conjunction with behavioral priming in an indirect memory task (though with a less posterior maximum), in that the latter was not modulated by semantic versus nonsemantic processing at study.

The familiarity signal associated with the FN400 may then derive predominantly from those words that were elaborated semantically at study, given that such semantic encoding is believed to increase both recollection and familiarity (Yonelinas, 2002). This is consistent with demonstrations that the FN400 is sensitive to semantic manipulations (see Paller et al., 2007; although it has also been shown to be sensitive to perceptual manipulations: GrohBordin, Zimmer, \& Ecker, 2006; Schloerscheidt \& Rugg, 2004). A similar association of the FN400 with conceptual processing and familiarity in recognition memory tests, but the association of a more posterior effect with perceptual fluency, was proposed by Nessler, Mecklinger, and Penney (2005) when using famous and nonfamous faces (see also Voss \& Paller, 2006).

Interpretation of the present fluency effect induced via masked repetition priming of test cues is less clear. As explained above, this effect was both temporally and spatially dissociable from the other three "memory" effects, with an earlier onset (150-250 msec) and a central distribution. Because we used masked repetitions of lexical stimuli, we cannot distinguish perceptual from conceptual contributions to this effect, except that the fluency must occur at a level of abstraction higher than letter case (which is not necessarily true for the long-lag priming effect). However, the persistence of the masked priming effect into the $300-500 \mathrm{msec}$ time window is consistent with modulation of the N400, a centrally distributed component that is most commonly associated with facilitated lexical and semantic processing of meaningful stimuli. The N400 is positively modulated (as found here) by the presentation of a word in a related relative to an unrelated context, such as a sentence stem (e.g., Kutas \& Hillyard, 1984), or a related word (as in semantic priming, e.g., Bentin, McCarthy, \& Wood, 1985). Indeed, Wolk et al. (2004) found that a sentence context not only modulated the N400 but also increased the bias to respond "old" in a recognition memory test, consistent with an attribution of conceptual fluency to past exposure. The N400 is also modulated by repetition of single words at relatively short lags, following unrelated category statements, and is dissociable from explicit memory effects (Olichney et al., 2000). 
It is a matter of debate, however, whether N400 semantic priming effects occur for unconsciously perceived (masked) primes (see, e.g., Kiefer \& Brendel, 2006; Holcomb, Reder, Misra, \& Grainger, 2005; Deacon, Hewitt, Yang, \& Nagata, 2000; Brown \& Hagoort, 1993). Holcomb and Grainger (2006) suggested that their N400 modulation by masked repetition priming, similar to that here, differed from the more conventional N400 modulation found in explicit semantic contexts. More specifically, because their N400 effect was also sensitive to partial letter overlap between prime and probe, they speculated that their effect reflected partial activation of lexical neighbors. Thus, one possibility is that the present masked priming effect reflects lexical-level activation that leads to a sense of fluency that can be attributed to prior exposure in the study list.

\section{How are Multiple “Memory" Signals Combined?}

It is clear from the present discussion that several neural signals could be interpreted as "memory" signals in that they are sensitive either to (a) the extent to which details of the encoding event are recollected, (b) an increased sense of familiarity with a stimulus, (c) simple prior exposure to a stimulus, or (d) increases in processing fluency that may be attributed to prior exposure. How do these various signals contribute to the eventual old-new recognition decision? More specifically, do these sources of evidence become available at different times after the onset of the test cue, and do they evolve independently or interactively?

Unfortunately, few studies have directly investigated how different memory signals interact over time, hence, we have little guidance to answer to these questions. Regarding their time courses, the results of the present study suggest at least that fluency signals induced by masked priming are available earliest ( $200 \mathrm{msec})$ and persist through the time window during which the familiarity and long-lag priming signals become evident ( $\sim 300 \mathrm{msec})$, and that recollection-related signals are available only later ( $\sim 500 \mathrm{msec})$. Consistent with this account, behavioral studies using response deadline procedures have provided evidence that cues to familiarity are available earlier than cues to recollection (e.g., Boldini, Russo, \& Avons, 2004). Note that this is not necessarily inconsistent with shorter RTs to make correct "old" judgments subsequently indicated as remembered versus subsequently indicated as known, as found here and in previous studies, in that although a familiarity signal may onset earlier than recollection, it may increase more gradually over time and take longer to surpass a response criterion.

The present finding that masked priming of test cues affected "old" judgments for know but not remember responses could then be explained if the signals underlying familiarity and recollection evolve independently, such that any increase in rise time or asymptote of the familiarity signal caused by masked priming is overriden by an independent recollection process (e.g., ignored in the presence of a probabilistic, all-or-none recollection signal; Yonelinas, Dobbins, Szymanski, Dhaliwal, \& King, 1996). ${ }^{3}$ A second possibility is that the signals do interact, but that participants always await the outcome of a search of episodic memory (i.e., recollection) before responding because it is a less ambiguous signal of prior exposure (consistent with the small number of false alarms indicated as remembered).

One potentially interesting result in the present study is that masked priming produced an earlier divergence in the ERPs for $\mathrm{R}$ hits and $\mathrm{K}$ hits (but not $\mathrm{K}$ hits vs. CRs), which might suggest that priming selectively accelerated recollection (i.e., that fluency and recollection signals are not independent). This was mirrored by faster RTs for primed versus unprimed $\mathrm{R}$ hits (although this speedup was also seen for primed vs. unprimed $\mathrm{K}$ hits). One possibility is that the earlier divergence of the R-K ERP effect following priming reflects a higher variability in the onset of this divergence across trials or participants (see Results). The reason for this is unclear. Alternatively, the earlier divergence of the $\mathrm{R}-\mathrm{K}$ effect may reflect a true decrease in the onset of recollection following priming. One possible reason for this may be that a prerequisite for a search of episodic memory for words is perceptual/lexical processing of those words. If so, and masked priming accelerates lexical access, recollection would occur earlier for primed than unprimed test cues. To explain why accelerated lexical access does not decrease the onset of the familiarity signal to the same extent, one might assume that the fluency induced by masked primes is a small part of the familiarity signal (i.e., just one of a large number of sources of "fluency," along with effects of prior study, word-frequency, etc., that can be combined into a familiarity signal). If $\mathrm{K}$ hits have high overall fluency, then there will be little scope for additional effects of masked priming on the latency of the familiarity effect. This is unlike R hits, which do not necessarily have high overall fluency, on average (if recollection is independent of the other sources of fluency). These issues clearly require further investigation.

\section{Potential Caveats}

We chose to identify the FN400 by the difference between $\mathrm{K}$ hits and misses and to examine separately the difference between misses and CRs (as in Rugg et al., 1998). The theoretical reason for this was to remove potential effects of implicit memory from the operationalization of familiarity (given that $\mathrm{K}$ hits and misses both correspond to items presented at study), and to remove potential effects of explicit memory from any remaining long-lag priming effects (given that both misses and CRs correspond to "new" judgments) as emphasized, for example, by Rugg and Curran (2007). These operationalizations are clearly not perfect, in that misses may 
involve a level of familiarity intermediate between hits and CRs, but below the participant's response criterion. Moreover, variables that affect encoding of a study item (such as level of selective attention) can clearly affect both familiarity and priming (Berry, Henson, \& Shanks, 2006; see also Paller et al., 2007). The strikingly different topographies of these two subtractions is evidence against these possibilities. Nonetheless, it remains possible that another factor may be relevant to misses (which appear in both subtractions) that does relate to encoding or storage in memory per se, such as level of selective attention to the test cue. Convergent evidence from experiments that operationalize familiarity and long-lag priming in ways other than recognition misses is clearly important in this respect. ${ }^{4}$

\section{Conclusion}

The present ERP data suggest that multiple neural signals potentially contribute to recognition memory, differing in terms of their time courses and underlying generators (as inferred from their different topographies). Such signals might include, for example, effects of prior exposure on perceptual, lexical, and semantic processing, in addition to possible episodic retrieval. In broad terms, these are consistent with multiple memory system theories. However, an important goal is to understand how these multiple signals are selected or combined in the service of a given memory task. For example, are they simply summated to form a single "strength of evidence" for an old-new recognition decision (as in signal-detection models, e.g., Wixted, 2007), do they may make independent contributions (e.g., Parks \& Yonelinas, 2007), or do they interact in some way? This question is itself difficult to answer without specifying how they evolve over time: Do the signals "race" independently to effect a decision (and at different rates), or do some occur earlier and influence others? Answers to these questions would seem to require new, dynamical models that are informed by both behavioral and neural data.

\section{Acknowledgments}

This work is supported by the UK Medical Research Council, and an Australian Research Council Grant and a Macquarie University Research Grant to Dr. Sachiko Kinoshita, to whom we are extremely grateful for help with the design and implementation of the research

Reprint requests should be sent to Richard N. Henson, MRC Cognition \& Brain Sciences Unit, 15 Chaucer Road, Cambridge, CB2 7EF, UK, or via e-mail: rik.henson@mrc-cbu.cam.ac.uk.

\section{Notes}

1. Interestingly, a few ERP studies of recognition memory have reported familiarity effects as early as this. For example, two studies using picture stimuli (Duarte et al., 2004; Tsivilis, Otten,
\& Rugg, 2001) found early familiarity effects that were maximal over fronto-polar sites. Two studies using word stimuli (Friedman, 2005; Curran \& Dien, 2003) found early familiarity effects that appeared to include fronto-polar components (using PCA in Curran \& Dien, 2003, or CSD in Friedman, 2005). We therefore followed up this trend for a $\mathrm{K}$ hit versus $\mathrm{CR}$ difference from 150 to $250 \mathrm{msec}$ with more focused analysis on frontopolar channels. However, no reliable effects were found, mainly because the difference had a more fronto-central distribution. Therefore, we chose not to pursue this potential early $\mathrm{K}$ hit versus CR effect further.

2. We have no evidence that our primes were truly subliminal, but the increase in false recognition is consistent with participants being unable to identify them (see Jacoby \& Whitehouse, 1989). In any case, their liminal or subliminal status is not critical to the implications of the dissociable patterns of ERP data for theories of recognition memory.

3. A related explanation is that the attribution of priminginduced fluency to the study phase only occurs for that subset of trials in which overall memory confidence is low, which would correspond low familiarity signals and an absence of recollection (Verfaellie \& Cermak, 1999). The main theoretical difference is that here recollection does not "override" familiarity; it simply does not occur.

4. One study that does support the validity of misses for examining memory effects is that of Bridson, Fraser, Herron, and Wilding (2006). When participants had to respond "old" to any repetition of a word (either from the study phase or from repeated unstudied words during the test phase), for which a familiarity signal would be sufficient, there was no reliable FN400 effect when contrasting misses and correct rejections, as was also the case here. However, when participants had to distinguish studied items from unstudied items, even when unstudied items were repeated, an FN400 effect was found for misses versus correct rejections. This was explained by assuming that familiarity was no longer a useful basis for an "old" judgment (only recollection was), so that misses now included highly familiar studied items that were not recollected.

\section{REFERENCES}

Bentin, S., McCarthy, G., \& Wood, C. C. (1985). Event-related potentials, lexical decision and semantic priming. Electroencephalography and Clinical Neurophysiology, 60, 343-355.

Berry, C. J., Henson, R. N., \& Shanks, D. R. (2006). On the relationship between repetition priming and recognition memory: Insights from a computational model. Journal of Memory and Language, 55, 515-533.

Berry, C. J., Shanks, D. R., \& Henson, R. N. (2008). A single-system account of the relationship between priming, recognition and fluency. Journal of Experimental Psychology, Learning, Memory, E Cognition, 34, 97-111.

Boldini, A., Russo, R., \& Avons, S. E. (2004). One process is not enough! A speed-accuracy tradeoff study of recognition memory. Psychonomic Bulletin E Review, 11, 353-361.

Bridson, N. C., Fraser, C. S., Herron, J. E., \& Wilding, E. L. (2006). Electrophysiological correlates of familiarity in recognition memory and exclusion tasks. Brain Research, 1114, 149-160.

Brown, C., \& Hagoort, P. (1993). The processing nature of the N400: Evidence from masked priming. Journal of Cognitive Neuroscience, 5, 34-44.

Buchner, A., \& Wippich, W. (2000). On the reliability of implicit and explicit memory measures. Cognitive Psychology, 40, 227-259. 
Coltheart, M. (1981). The MRC psycholinguistic database. Quarterly Journal of Experimental Psychology, 33A, 497-505.

Conroy, M. A., Hopkins, R. O., \& Squire, L. R. (2005). On the contribution of perceptual fluency and priming to recognition memory. Cognitive, Affective \& Behavioral Neuroscience, 5, 14-20.

Curran, T. (2000). Brain potentials of recollection and familiarity. Memory \& Cognition, 28, 923-938.

Curran, T., \& Dien, J. (2003). Differentiating amodal familiarity from modality-specific memory processes: An ERP study. Psychophysiology, 40, 979-988.

Deacon, D., Hewitt, S., Yang, C. M., \& Nagata, M. (2000). Event-related potential indices of semantic priming using masked and unmasked words: Evidence that the N400 does not reflect a post-lexical process. Cognitive Brain Research, 9, 137-146.

Duarte, A., Ranganath, C., Winward, L., Hayward, D., \& Knight, R. T. (2004). Dissociable neural correlates for familiarity and recollection during the encoding and retrieval of pictures. Brain Research, Cognitive Brain Research, $18,255-272$.

Forster, K. I., \& Forster, J. C. (1990). The DMASTR display system for mental chronometry. Tucson: University of Arizona.

Friedman, D. (2005). ERP studies of recognition memory: Differential effects of familiarity, recollection and episodic priming. Cognitive Sciences, 1, 81-121.

Gabrieli, J. D. (1998). Cognitive neuroscience of human memory. Annual Review of Psychology, 49, 87-115.

Gabrieli, J. D. E., Fleischman, D. A., Keane, M. M., Reminger, S. L., \& Morrell, F. (1995). Double dissociation between memory systems underlying explicit and implicit memory in the human brain. Psychological Science, 6, 76-82.

Graf, P., Squire, L. R., \& Mandler, G. (1984). The information that amnesic patients do not forget. Journal of Experimental Psychology: Learning, Memory, and Cognition, 10, 164-178.

Groh-Bordin, C., Zimmer, H. D., \& Ecker, U. K. H. (2006). Has the butcher on the bus dyed his hair? When color changes modulate ERP correlates of familiarity and recollection. Neuroimage, 32, 1879-1890.

Hamann, S. B., \& Squire, L. R. (1997). Intact perceptual memory in the absence of conscious memory. Behavioral Neuroscience, 111, 850-854.

Herron, J. E., \& Rugg, M. D. (2003). Strategic influences on recollection in the exclusion task: Electrophysiological evidence. Psychonomic Bulletin \& Review, 10, 703-710.

Higham, P. A., \& Vokey, J. R. (2000). Judgment heuristics and recognition memory: Prime identification and target processing fluency. Memory \& Cognition, 28, 574-584.

Holcomb, P. J., \& Grainger, J. (2006). On the time course of visual word recognition: An event-related potential investigation using masked repetition priming. Journal of Cognitive Neuroscience, 18, 1631-1643.

Holcomb, P. J., Reder, L., Misra, M., \& Grainger, J. (2005). The effects of prime visibility on ERP measures of masked priming. Cognitive Brain Research, 24, 155-172.

Jacoby, L. L., \& Dallas, M. (1981). On the relationship between autobiographical memory and perceptual learning. Journal of Experimental Psychology: General, 110, 306-340

Jacoby, L. L., \& Whitehouse, K. (1989). An illusion of memoryFalse recognition influenced by unconscious perception. Journal of Experimental Psychology: General, 118, 126-135.

Jernigan, T. L., \& Ostergaard, A. L. (1993). Word priming and recognition memory are both affected by mesial temporal lobe damage. Neuropsychology, 1, 14-26.
Joordens, S., \& Merikle, P. M. (1992). False recognition and perception without awareness. Memory \& Cognition, 30, 151-159.

Kiefer, M., \& Brendel, D. (2006). Attentional modulation of unconscious "automatic" processes: Evidence from event-related potentials in a masked priming paradigm. Journal of Cognitive Neuroscience, 18, 184-198.

Kinoshita, S. (1997). Masked target priming effects on feeling-of-knowing and feeling-of-familiarity judgments. Acta Psychologica, 97, 183-199.

Kucera, H., \& Francis, W. N. (1967). Computational analysis of present-day American English. Providence, RI: Brown University Press.

Kutas, M., \& Hillyard, S. A. (1984). Brain potentials during reading reflect word expectancy and semantic association. Nature, 307, 161-163.

Mandler, G. (1980). Recognizing: The judgement of previous occurrence. Psychological Review, 87, 252-271.

McCarthy, G., \& Wood, C. C. (1985). Scalp distributions of event-related potentials: An ambiguity associated with analysis of variance models. Electroencephalography and Clinical Neurophysiology, 62, 203-208.

Nessler, D., Mecklinger, A., \& Penney, T. B. (2005). Perceptual fluency, semantic familiarity and recognition-related familiarity: An electrophysiological exploration. Brain Research, Cognitive Brain Research, 22, 265-288.

Olichney, J. M., Van Petten, C., Paller, K. A., Salmon, D. P., Iragui, V. J., \& Kutas, M. (2000). Word repetition in amnesia. Electrophysiological measures of impaired and spared memory. Brain, 123, 1948-1963.

Paller, K. A., Voss, J. L., \& Boehm, S. G. (2007). Validating neural correlates of familiarity. Trends in Cognitive Sciences, 11, 243-250.

Parks, C. M., \& Yonelinas, A. P. (2007). Moving beyond pure signal-detection models: Comment on Wixted (2007). Psychological Review, 114, 188-202; discussion 203-189.

Picton, T. W., Bentin, S., Berg, P., Donchin, E., Hillyard, S. A., Johnson, R., Jr., et al. (2000). Guidelines for using human event-related potentials to study cognition: Recording standards and publication criteria. Psychophysiology, 37, 127-152.

Poldrack, R. A., \& Logan, G. D. (1998). What is the mechanism for fluency in successive recognition? Acta Psychologica, 98, 167-181.

Rajaram, S. (1993). Remembering and knowing: Two means of access to the personal past. Memory \& Cognition, 21, 89-102.

Richardson-Klavehn, A., \& Bjork, R. A. (1988). Measures of memory. Annual Review of Psychology, 39, 475-543.

Roediger, H. L., \& McDermott, K. B. (1993). Implicit memory in normal human subjects. In F. Boller \& J. Grafman (Eds.), Handbook of neuropsychology (Vol. 8, pp. 63-161). Amsterdam: Elsevier.

Rugg, M. D., \& Coles, M. G. H. (Eds.). (1995). Electrophysiology of mind. Oxford: Oxford University Press.

Rugg, M. D., \& Curran, T. (2007). Event-related potentials and recognition memory. Trends in Cognitive Sciences, 11, 251-257.

Rugg, M. D., Mark, R. E., Walla, P., Schloerscheidt, A. M., Birch, C. S., \& Allan, K. (1998). Dissociation of the neural correlates of implicit and explicit memory. Nature, 392, 595-598.

Schacter, D. L. (1987). Implicit memory: History and current status. Journal of Experimental Psychology, 13, 501-518.

Schloerscheidt, A. M., \& Rugg, M. D. (2004). The impact of change in stimulus format on the electrophysiological indices of recognition. Neuropsychologia, 42, 451-466. 
Schnyer, D. M., Allen, J. J., \& Forster, K. I. (1997). Event-related brain potential examination of implicit memory processes: Masked and unmasked repetition priming. Neuropsychology, 11, 243-260.

Smith, M. E. (1993). Neurophysiological manifestations of recollective experience during recognition memory judgements. Journal of Cognitive Neuroscience, 5 , $1-13$.

Squire, L. R. (1994). Memory and forgetting: Long-term and gradual changes in memory storage. International Review of Neurobiology, 37, 243-269; discussion 285-248.

Stark, C. E., \& Squire, L. R. (2000). Recognition memory and familiarity judgments in severe amnesia: No evidence for a contribution of repetition priming. Behavioral Neuroscience, 114, 459-467.

Tsivilis, D., Otten, L. J., \& Rugg, M. D. (2001). Context effects on the neural correlates of recognition memory: An electrophysiological study. Neuron, 31, 497-505.

Tulving, E. (1985). Memory and consciousness. Canadian Psychologist, 26, 1-12.

Tulving, E., \& Schacter, D. L. (1990). Priming and human memory systems. Science, 247, 301-306.

Urbach, T. P., \& Kutas, M. (2002). The intractability of scaling scalp distributions to infer neuroelectric sources. Psychophysiology, 39, 791-808.

Verfaellie, M., \& Cermak, L. S. (1999). Perceptual fluency as a cue for recognition judgments in amnesia. Neuropsychology, 13, 198-205.

Vilberg, K. L., Moosavi, R. F., \& Rugg, M. D. (2006). The relationship between electrophysiological correlates of recollection and amount of information retrieved. Brain Research, 1122, 161-170.

Voss, J. L., \& Paller, K. A. (2006). Fluent conceptual processing and explicit memory for faces are electrophysiologically distinct. Journal of Neuroscience, 26, 926-933.

Wagner, A. D., \& Gabrieli, J. D. (1998). On the relationship between recognition familiarity and perceptual fluency:

Evidence for distinct mnemonic processes. Acta Psychologica (Amsterdam), 98, 211-230.

Warrington, E. K., \& Weiskrantz, L. (1974). The effect of prior learning on subsequent retention in amnesic patients. Neuropsychologia, 12, 419-428.

Whittlesea, B. W., \& Williams, L. D. (2000). The source of feelings of familiarity: The discrepancy-attribution hypothesis. Journal of Experimental Psychology: Learning, Memory, and Cognition, 26, 547-565.

Wilding, E. L. (2000). In what way does the parietal ERP $\mathrm{old} / \mathrm{new}$ effect index recollection? International Journal of Psychophysiology, 35, 81-87.

Wixted, J. T. (2007). Dual-process theory and signal-detection theory of recognition memory. Psychological Review, 114, 152-176.

Wolk, D. A., Schacter, D. L., Berman, A. R., Holcomb, P. J., Daffner, K. R., \& Budson, A. E. (2004). An electrophysiological investigation of the relationship between conceptual fluency and familiarity. Neuroscience Letters, 369, 150-155.

Yonelinas, A. P. (2001). The nature of recollection and familiarity: A review of 30 years of research. Journal of Memory and Language, 46, 441-517.

Yonelinas, A. P. (2002). The nature of recollection and familiarity: A review of 30 years of research. Journal of Memory and Language, 46, 441-517.

Yonelinas, A. P., Dobbins, I., Szymanski, M. D., Dhaliwal, H. S., \& King, L. (1996). Signal-detection, threshold, and dual-process models of recognition memory: ROCs and conscious recollection. Consciousness and Cognition, 5, 418-441. 